Conclusions An ICU stay can have significant, long-lasting impacts on young people and their families. This is the first panEuropean survey to investigate ICU care for this group. We identified significant variation in adherence to quality standards. Some of this may be culturally influenced but there are also differences in less obviously controversial measures e.g. DVT prophylaxis. Further qualitative work is planned.

\section{Big Data Studies}

\section{0-006 FOLLOW - UP OUTCOMES FROM THE BOOST-II UK TRIAL OF OXYGEN SATURATION TARGETING IN PRETERM INFANTS}

B Stenson, P Brocklehurst, P Cairns, S Deshpande, BW Fleck, HL Halliday, E Juszzzak, A King, N Marlow, W Tin, S Wardle. BOOST II UK Collaborative Group, National Perinatal Epidemiology Unit, Oxford, UK

\subsection{6/archdischild-2014-307384.73}

Background and aims The optimal target range for pulse oximeter saturation $\left(\mathrm{SpO}_{2}\right)$ in extremely preterm infants is unknown. BOOST-II UK is one of 5 international studies that have recently investigated this.

Methods Preterm infants born before 28 weeks' gestation were randomised within $24 \mathrm{~h}$ of birth to an $\mathrm{SpO}_{2}$ target range of 85$89 \%$ or $91-95 \%$. The intervention used masked offset oximeters and was continued until 36 weeks' gestation. The primary outcome was a composite of death or serious neurosensory disability (SND) in survivors at age 2 corrected for prematurity, evaluated in 745 infants cared for using updated trial oximeters. A sensitivity analysis restricted to infants assessed by a Bayley III examination and a secondary analysis including a further 228 infants who were studied before the oximeters were updated were also performed.

Results The primary outcome was determined for 722 (96.9\%) of infants.

\begin{tabular}{|c|c|c|c|c|}
\hline & $\begin{array}{l}\text { Lower } \mathrm{SpO}_{2} \text { target } \\
(85-89 \%)\end{array}$ & $\begin{array}{l}\text { Higher } \mathrm{SpO}_{2} \text { target } \\
(91-95 \%)\end{array}$ & $\begin{array}{l}\text { Adjusted risk ratio } \\
\left(^{*}=95 \% \mathrm{Cl}, \dagger=99 \% \mathrm{Cl}\right)\end{array}$ & $P$ value \\
\hline Death or SND & $187 / 366(51.1 \%)$ & $165 / 356(46.3 \%)$ & $1.11(0.98-1.26)^{*}$ & 0.11 \\
\hline Death & $101 / 371(27.2 \%)$ & $69 / 369(18.7 \%)$ & $1.38(1.0-1.9) \dagger$ & 0.01 \\
\hline SND & $86 / 265(32.5 \%)$ & 96/287 (33.4\%) & $1.01(0.76-1.34)+$ & 0.96 \\
\hline
\end{tabular}

The sensitivity analysis showed similar results. In the secondary analysis the mortality difference was $4.9 \%(\mathrm{p}=0.05)$. Severe visual loss did not differ between groups.

Conclusions The higher $\mathrm{SpO}_{2}$ target group had $8.5 \%$ greater survival with no increase in serious neurosensory disability. For infants born before 28 weeks" gestation, $\mathrm{SpO}_{2}$ targets below $90 \%$ are not recommended.

\section{0-007 NEONATAL HYPOGLYCEMIA: INTENSIVE TREATMENT OR EXPECTANT MONITORING?}

${ }^{1}$ AAMW van Kempen, ${ }^{2} \mathrm{PF}$ Eskes, ${ }^{3} \mathrm{JH}$ Kok, ${ }^{4} \mathrm{~N}$ Boluyt. ${ }^{1}$ Neonatology, OLVG Hospital, Amsterdam, Netherlands; ${ }^{2}$ Pediatrics, Meander Medical Center, Amersfoort, Netherlands; ${ }^{3}$ Neonatology, Emma Children's Hospital/AMC, Amsterdam, Netherlands; ${ }^{4}$ NA, National Health Care Institute, Diemen, Netherlands

10.1136/archdischild-2014-307384.74
Background The definition of neonatal hypoglycemia is still subject to discussion, resulting in a wide range of treatment protocols.

Objective To compare two expert-based management strategies at both ends of the current treatment-spectrum of 'moderate' neonatal hypoglycemia (plasma glucose $2.0-2.5 \mathrm{mmol} / \mathrm{l}$ ).

Design/methods Otherwise healthy, 'high-risk' newborns $\geq 35$ weeks and $\geq 2000$ gram with moderate hypoglycemia: premature, small- or large-for-gestational-age or infants of diabetic mothers, were randomised to an intensive treatment strategy (aiming at [glucose] $\geq 2.6 \mathrm{mmol} / \mathrm{l}$ ) or an expectant monitoring strategy (aiming at [glucose] $\geq 2.0 \mathrm{mmol} / \mathrm{l})$. Development was assessed at 18 months (corrected) age, using the Bayley Scales of Infant Development (BSID-III). The study was designed as a non-inferiority trial.

Results In $84 \%$ of the 691 enrolled infants the BSID-III was performed. Cognitive and motor outcomes were comparable in both treatment arms (Table). The results were similar in the overall analysis and in the subgroups.

\begin{tabular}{|c|c|c|c|}
\hline & Intensive Treatment & Expectant Monitoring & Mean Difference $(95 \% \mathrm{Cl})$ \\
\hline BSID-Cognitive & $103.6 \pm 10.9$ & $104.6 \pm 11.4$ & $1.0(-0.8 ;+2.8)$ \\
\hline BSID-Motor & $101.8 \pm 10.6$ & $101.6 \pm 11.7$ & $-0.2(-2.1 ;+1.6)$ \\
\hline
\end{tabular}

The plasma glucose concentration was higher in the intensive treatment group: $+0.24 \mathrm{mmol} / 1(+0.31 ;+0.16)$. Hypoglycemia episodes (after randomization) occurred more frequently in the expectant monitoring group (70\% vs. 57\%, p < 0.001). More infants in the intensive treatment group received additional feeding (94\% vs. $76 \%)$, tube-feeding (12\% vs. $4 \%)$ and/or intravenous glucose $(20 \%$ vs. $6 \%)$ (all: $\mathrm{p}<0.001)$.

Conclusion An expectant monitoring strategy is not inferior to intensive treatment with regard to developmental outcome at 18 months in otherwise healthy newborn infants $\geq 35$ weeks and $\geq 2000$ gram with moderate hypoglycemia.

\section{0-008 EARLY BIFIDOBACTERIUM BREVE BBG-001 TO PREVENT NECROTISING ENTEROCOLITIS, LATE-ONSET SEPSIS AND DEATH: THE PIPS TRIAL}

${ }^{1} \mathrm{KL}$ Costeloe, ${ }^{2} \mathrm{M}$ Wilks, ${ }^{3} \mathrm{P}$ Hardy, ${ }^{3} \mathrm{C}$ Nelis, ${ }^{2} \mathrm{MR}$ Millar. ${ }^{1}$ Paediatrics, Queen Mary University of London, London, UK; ${ }^{2}$ Microbiology, Barts Health NHS Trust, London, UK; ${ }^{3}$ National Perinatal Epidemiology Unit, University of Oxford, Oxford, UK

\subsection{6/archdischild-2014-307384.75}

Background Interpretation of published trials of probiotics in preterm infants is complicated by the use of multiple bacterial strains and exclusion from some trials of babies at high-risk of complications.

Objective To evaluate a single strain of Bifidobacterium breve in an unselected population of preterm infants.

Methods Multi-centre double blind Randomised Placebo Controlled Trial of Bifidobacterium breve BBG-001, 2.1 to $5.3 \times 10^{8}$ cfu daily, ( $B$ breve) in infants below $31 \mathrm{w}$ gestation randomised before $48 \mathrm{~h}$. Primary outcomes were necrotising enterocolitis (NEC) $\geq$ Bell stage 2, late onset sepsis (LOS) and death. Results are presented by intention to treat adjusted for sex, gestation and randomisation within $24 \mathrm{~h}$ and allowing for clustering of multiples. 
Results 1310 infants were randomised, median gestation 28.0w, median birthweight $1010 \mathrm{~g}$ and median age starting the intervention $44 \mathrm{~h}$. No adverse events related to the intervention were reported.

\begin{tabular}{llll} 
Abstract 0-008 & Table 1 & & \\
\hline & B breve, $\mathbf{n = 6 5 0}$ & Placebo, $\mathbf{n}=660$ & Adjusted RR (95\% Cl) \\
NEC $\geq$ Bell stage 2 & $61(9.4 \%)$ & $66(10.0 \%)$ & $0.93(0.68$ to 1.27$)$ \\
LOS & $73(11.2 \%)$ & $77(11.7 \%)$ & $0.97(0.73$ to 1.29$)$ \\
Death & $54(8.3 \%)$ & $56(8.5 \%)$ & $0.93(0.67$ to 1.30$)$ \\
\hline
\end{tabular}

Conclusions This intervention was not associated with any advantage in this population of babies. This result highlights the need to assess the efficacy of different probiotic strains and challenges the validity of combining trials using different probiotic interventions in meta-analyses.

\section{0-009 LONGITUDINAL DEVELOPMENTAL EFFECTS OF THE INFANT BEHAVIOURAL ASSESSMENT AND INTERVENTION PROGRAM IN VERY LOW BIRTH WEIGHT INFANTS}

${ }^{1} \mathrm{~J}$ Van Hus, ${ }^{1} \mathrm{M}$ Jeukens-Visser, ${ }^{1} \mathrm{~K}$ Koldewijn, ${ }^{2} \mathrm{R}$ Holman, ${ }^{3} \mathrm{H}$ Kok, ${ }^{1} \mathrm{~F}$ Nollet, ${ }^{3} \mathrm{~A}$ Van Wassenaer-Leemhuis. ${ }^{1}$ Rehabilitation, Academic Medical Center, Amsterdam, Netherlands, ${ }^{2}$ Clinical Research Unit, Academic Medical Center, Amsterdam, Netherlands; ${ }^{3}$ Neonatology, Academic Medical Center, Amsterdam, Netherlands

\subsection{6/archdischild-2014-307384.76}

Background Cross-sectional analyses at 6, 12, 24 months and 5.5 years, revealed positive intervention effects on child development in VLBW infants who were supported by the Infant Behavioural Assessment and Intervention Program $\subset$ (IBAIP) as comparing to standard follow-up care. Longitudinal effects were not analysed yet.

AIM To investigate the longitudinal effects of the IBAIP in VLBW infants on cognitive and motor development.

Methods In a RCT, 86 VLBW infants received the IBAIP until 6 months CA, 90 VLBW infants received standard care. At 6, 12, and 24 months CA, cognitive and motor development were assessed with the Bayley Scales of Infant Development. At 5.5 years CA the Wechsler Preschool and Primary Scale of Intelligence and the Movement Assessment Battery for Children were used. Longitudinal data were analysed with linear mixed models in total group and three subgroups, using Z-scores generated from raw cognitive and motor scores.

Results A significant intervention effect $(0.4 \mathrm{SD})$ on motor development was found $(\mathrm{p}=0.006)$. On cognitive development, a non-significant intervention effect over time was found $(\mathrm{p}=$ 0.063). In children with bronchopulmonary dysplasia (BPD) significant intervention effects were found for both cognitive (effect=0.7SD; $p=0.019$ ) and motor (effect=0.9SD; p = 0.026 ) outcome. Maternal education hardly influenced intervention effects over time, but in children with combined biological and social risks a longitudinal intervention effect of $0.8 \mathrm{SD}$ was found on cognitive development $(\mathrm{p}=0.044)$.

Conclusion The IBAIP leads to improved motor development in VLBW infants, and in infants with BPD also to improved cognitive development, over a five years period after the intervention.
$0-009 a$

THE PAEDIATRIC OBSERVATION PRIORITY SCORE (POPS): OUTCOMES OF 24000 PATIENTS

${ }^{1} \mathrm{D}$ Roland, ${ }^{1} \mathrm{~F}$ Davies, ${ }^{2} \mathrm{~T}$ Coats. ${ }^{1}$ Paediatric Emergency Medicine Leicester Academic (PEMLA) Group, University Hospitals of Leicester NHS Trust, Leicester, UK; ${ }^{2}$ Cardiovascular Sciences, Leicester University, Leicester, UK

\subsection{6/archdischild-2014-307384.77}

Background The Paediatric Observation Priority Score (POPS) (see Figure) has been designed as a triage tool and illness identification system to aid disposition and discharge decisions.

Methods A unique data-collection method was set up whereby the key parameters of POPS were inputted onto a web-based data entry sheet. All children 0-15 presenting with any condition were included except those presenting straight to the resuscitation room. Data was collated with the hospital's Emergency Department Information System and information from inpatient hospital systems.

Results After data cleaning 24068 records were available for review between the period of August 2012 and December 2013. 2870 patients were admitted (11.9\%). The majority of patients (16475) were POPS 0 (Table 1) and of these 794 (4.8\%) were admitted to the hospital. Only 11 children discharged with POPS 0 returned to be admitted and required further definitive management. There was a correlation between initial POPS and average hospital stay (Pearsons correlation $-0.83, \mathrm{r} 2=0.92)$. The receiver operating characteristic (ROC) curve was 0.802 for POPS values sectioned into categories $\{0,1-2,3-4,5-7$ and $8+\}$ at predicting admission.

Conclusion POPS demonstrates utility as a patient safety system and a means to plan resources. The ROC is comparable with paediatric early warning scores systems utilised in Children's Emergency Departments. There are significant risks in managing the acutely ill child but the introduction of POPS may assist in reducing unnecessary admission and prevent episodes of missed or incorrect diagnosis.

\section{Abstract 0-009a Table 1}

\begin{tabular}{|l|l|l|}
\hline POPS & $\begin{array}{l}\text { Patients } \\
\text { Presenting }\end{array}$ & $\begin{array}{l}\text { Admissions } \\
\text { (Percentage) }\end{array}$ \\
\hline 0 & 16475 & $794(4.8 \%)$ \\
\hline 1 & 3110 & $552(17.7 \%)$ \\
\hline 2 & 1701 & $429(25.2 \%)$ \\
\hline 3 & 1050 & $302(28.8 \%)$ \\
\hline 4 & 707 & $248(35.1 \%)$ \\
\hline 5 & 471 & $219(46.5 \%)$ \\
\hline 6 & 311 & $167(53.7 \%)$ \\
\hline 7 & 140 & $87(62.1 \%)$ \\
\hline 8 & 67 & $46(68.7 \%)$ \\
\hline 9 & 28 & $19(67.9 \%)$ \\
\hline 10 & 5 & $4(80 \%)$ \\
\hline 11 & 2 & $2(100 \%)$ \\
\hline 12 & 1 & $1(100 \%)$ \\
\hline Total & 24068 & $2870(11.9 \%)$ \\
\hline
\end{tabular}

